\title{
Psychological impact of mandatory COVID-19 quarantine on small business owners and self-employed in China
}

\author{
Wei Wang ${ }^{1} \cdot$ Wenjing Huang ${ }^{1} \cdot$ Xiaoxue Liu $^{2} \cdot$ Dwight A. Hennessy ${ }^{3}$ \\ Accepted: 7 June 2021 \\ (C) The Author(s), under exclusive licence to Springer Science+Business Media, LLC, part of Springer Nature 2021
}

\begin{abstract}
A massive home-quarantine took place in China due to the novel coronavirus in the end of 2019. The purpose of the present study was to explore the potential mental health impact of this forced quarantine and widespread shutdown among small business owners and the self-employed. A semi-structured interview was employed among 14 participants from three different cities in China. Grounded Theory was employed to analyze the data using Nvivo11 plus. Based on a qualitative analysis, 9 categories of responses emerged to describe the experience and actions of participants towards the quarantine: enjoyment of life, emotional disturbance, hope, comparisons to others, social support, patriotism, making changes, and obedience. Further analysis suggested that the mental state of participants was either positive or negative depending on enjoyment of life, loss, emotional disturbance, and hope, and that these were impacted by intervening conditions (national measures, social support, patriotism), personal strategies (exercising, studying, comparisons to others), and personal consequences (making change, obedience). Rather than observing a linear pattern of negative outcomes, mental state was found to be variable in that positive outcomes were experienced earlier in the quarantine (making connections with family), negative states were encountered midway through the quarantine (fear of financial loss, anxiety), and more positive mental states (hope) emerged towards the end of the quarantine depending on intervening conditions, personal strategies, and consequences. It can be concluded that the nature of the impact of mandatory quarantine in China among small business owners and the self-employed is complex and depends on a variety of personal and situational factors.
\end{abstract}

Keywords Home-quarantine $\cdot$ Psychological impact $\cdot$ Business owners $\cdot$ COVID-19

\section{Introduction}

In December 2019 an unknown pneumonia-like viral illness (later named COVID-19 and linked to the Novel Coronavirus) appeared in Wuhan, Hubei Province, China (World Health Organization, January 20, 2020). Since strong evidence suggested that the Novel Coronavirus was highly contagious through interpersonal contact (National Health Commission of the People's Republic of China, 2020), the city of Wuhan was locked down on January 23rd, 2020. One thing that made

Dwight A. Hennessy

hennesda@buffalostate.edu

1 Weifang Medical University School of Health Management, 7166 Baotongxi Street, Weifang City 261053, Shandong Province, China

2 Jinan City Center of Disease Control, 2 Weiliu Road, Huaiyin District, Jinan City 250021, Shandong Province, China

3 State University of New York, Buffalo State, Department of Psychology, 1300 Elmwood Avenue, Buffalo, NY 14222, USA this virus so problematic was that, despite its high degree of infectiousness, many did not show obvious symptoms. As a result, it was spread rapidly by asymptomatic individuals (Dimaschko et al., 2021). As a new virus, there was no available evidence at that time to direct policy or procedure, so it appeared that the best course of action was to physically isolate people in order to curb the spread of infection. Swift and decisive action was required at that time given that an estimated 5 million citizens of Wuhan had just previously departed the city to visit their hometowns throughout China to celebrate the Chinese New Year (Wang \& Zhang, 2020). Therefore, it was deemed necessary to take such draconian actions to halt the rapid expansion and spread of this virus.

Due to the fact that so many had departed Wuhan and Hubei province (the epicenter of the virus and disease) during the holiday season, reports of infection from around China began to emerge. As a result, authorities from all provinces and administrative divisions of China launched the highestlevel response to this health emergency through a massive lockdown of the country involving tens of millions of people, 
which is believed to be the largest quarantine in human history at that time (Gunia, 2020; Huang, 2020; Zhang, 2020). Some of the specific lockdown measures that were taken included shutting down public transportation systems, restricting travel, and closing supermarkets, stores, malls, fairs and any place where crowds of people could congregate (Langton, 2020). People were ordered to stay at home and were only allowed to go out to shop for basic supplies once or twice a week with permission. Those who were sick were advised to stay home and leave only to visit a doctor. This measure prevented many who had travelled to visit family during the Chinese New Year (which is considered the most important festival in China) from returning to their own homes. Also, since this was a break period in the education system prior to the start of a new semester, education authorities made the decision to suspend upcoming in-school classes and activities. As an alternative, virtual courses were given for students at all levels of education to ensure they were maintaining their educational training but were also protected from the Novel Coronavirus (Huaxia, 2020). These shutdown actions also meant that nearly all places of business, including restaurants, grocery stores, department stores, barber shops, clothing stores, pharmacies, and open markets, were ordered to close. The exceptions were a few stores that provided basic requirements, which were allowed to open for a few hours a day to serve the need for food, medicine, and other life necessities.

According to many experts, any form of physical isolation, like quarantine and shelter-in-place, can effectively stop the spread of an infection, and ultimately prevent further illness and harm (Dailey \& Kaplan, 2014; Usher et al., 2020). As such, current evidence does suggest that these drastic measures of imposing travel bans and closing schools/businesses successfully reduced the virus' reproduction and transmission (PTI, 2020). Similarly, the imposition of regulations regarding face masks and social distancing when in pubic were also shown to decrease the spread of the COVID-19 disease (Le et al., 2020; Tran et al., 2020; Wang et al., 2020a), highlighting the positive health benefits of such efforts.

However, there are also demonstrable concerns over the negative consequences of these actions. For example, a noteworthy longitudinal study found high levels of depression, anxiety, and stress outcomes in the early months of the Coronavirus in China (Wang et al., 2020b; Wang et al., 2020c) which had not significantly declined after four months. Similarly, the prolonged isolation from lockdown measures is believed to exaggerate psychological problems such as anxiety, depression, and loneliness - especially for those who may have preexisting vulnerability (Usher et al., 2020). One potential explanation for this is Strain Theory which posits that competing or conflicting pressures in life create psychological tension, which can build and eventually manifest as negative psychological outcomes (Zhang, 2005). In particular, coping strain (conflict from the inability to deal with life challenges or difficulties) and aspiration strain (competition between an individual's aspirations or goals and the realities of a given situation) have been found to increase psychological distress (Ren et al., 2018) and depression (Zhang et al., 2016). In this context, the inability to cope with these sudden and dramatic health and safety issues and the resulting forced lockdown, in addition to difficulties in achieving the desired goal of working and providing for their families may have increased levels of strain and ultimately incited psychological issues.

Previous research has specifically highlighted the negative psychological consequences stemming from the economic concerns following sudden unemployment and lost income during forced lockdown, which can lead to marked levels of elevated stress (Le et al., 2020; Tran et al., 2020). In this respect, employment factors have been previously found to distinctly increase coping and aspirations strains, leading to increased depression and suicide in China (Liu et al., 2019; Zhou et al., 2018). A recent report by Zhang et al. (2020) noted that the widespread shutdown in China may have the greatest economic impact on small business owners and the self-employed. This may be because this group have a larger personal investment in their financial situation, tend to have less "cash-on-hand" to meet business expenses, are less able to absorb inventory loss, and may not receive aid/assistance as readily as larger businesses during the lockdown. Therefore, the present manuscript is focused on the potential psychological impact of the long-term home-quarantine in China on small business owners and the self-employed.

Previous research on this process is limited, due to the fact that quarantine and physical isolation are not common events - particularly in this magnitude. Further, the research that has examined the mental health or psychological impact related to quarantine or physical isolation, has mainly focused on respondents who were confirmed cases who had been exposed to dangerous pathogens (Kim et al., 2018; Lee et al., 2018; Maunder et al., 2003) or older individuals who live alone (Gyasi et al., 2019). To date, little is known about the large number of small business owners and the self-employed individuals who have been physically isolated at home while their business has been forcibly shut down. As a result, the current study aimed to investigate small business owners and selfemployed individuals, in order to examine their experiences from the widespread mandatory quarantine measures in China, and to explore possible negative psychological consequences. The hypotheses of the current study were that 1) the long-term home-quarantine will impose a psychological impact on small business owners and the self-employed; 2) the long-term home-quarantine will result in negative mental states for these individuals.

The following sections of this manuscript will describe how the sample was obtained and how the interview process was structured/conducted. Next, the method and steps involved in the qualitative analyses are explained. The 
categories extracted from this coding process are then described, along with the paradigmatic model that emerged, and the final central categories. Finally, these outcomes are discussed, implications are drawn, and conclusions are offered.

\section{Method}

A descriptive qualitative design was used for this study (see Fig. 1) based on the following research questions:

RQ1: How did the participants feel during the quarantine time in general?

RQ2: Did they experience social support from others (family, friends, government) and how did they respond to this support?

RQ3: How did they get along with their loved ones during the lockdown?

RQ4: How did they react to COVID-19 and the situation in Wuhan?

RQ5: Was their basic life situation altered during the quarantine and, if so, how?

RQ6: What were their reactions to the forced shutdown of their business?

RQ7: What were their plans for the future?

All study protocols were approved by the Research Ethics Boards of Weifang Medical University. Sample inclusion criteria were 1) small business owners or self-employed individuals with a business that was shut down during the quarantine period in China and 2) only individuals who were completely physically isolated from outside contact except going out for basic supplies occasionally during the first level of emergency response period from January 31st to at least March 7th.

\section{Sample and Data Collection}

Purposive sampling was conducted to obtain participants in three cities in Shandong Province in China. Initially, potential small and self-employed business owners were recommended to the three Chinese authors by personal contacts. From that list, a total of five participants were then obtained in each of three different cities: Xintai City, Huantai City, and Weifang City. However, the final sample included only 14 participants because one business owner went on a business trip and cancelled the interview in Huantai City. The remaining participants all provided informed consent ahead of the interview. All participants were interviewed individually by the respective three authors in China who had made the initial contact. During the interview, participants were asked to recall and describe their experiences and how they felt during the isolation period while their business was shut down. All interviews lasted between 30 and $72 \mathrm{~min}$, and were audiotaped for subsequent verbatim transcription. The interviews took place from May 1-15, 2020. Basic participant demographic characteristics can be found in Table 1. Actual names of the participants are not used for the sake of privacy.

\section{Measurements}

A semi-structured interview was employed, with both open and closed ended questions. The closed ended questions included descriptive characteristics (gender, age, occupation, education, economic status, marital status, family atmosphere). The open ended questions were constructed based on Social Support Theory (Liu et al., 2008; Xiao, 1994) and the 12-Item Grit Scale (Xie et al., 2017) which were used as a guide for the interview. During the interview process, participants were asked to describe their experiences and feelings surrounding the quarantine, how others provided social support and their concerning responses, what they thought about the shutdown of their business, how they reacted to COVID19 and the situation in Wuhan, their basic life situation during the time of quarantine, and their thoughts and feelings about their future.

\section{Data Analyses}

The transcriptions were imported into Nvivo11 Plus and analyzed based on Grounded Theory. From this data analysis, an explanatory framework was created (Chen, 2000; Santos
Fig. 1 Flowchart of methodological approach

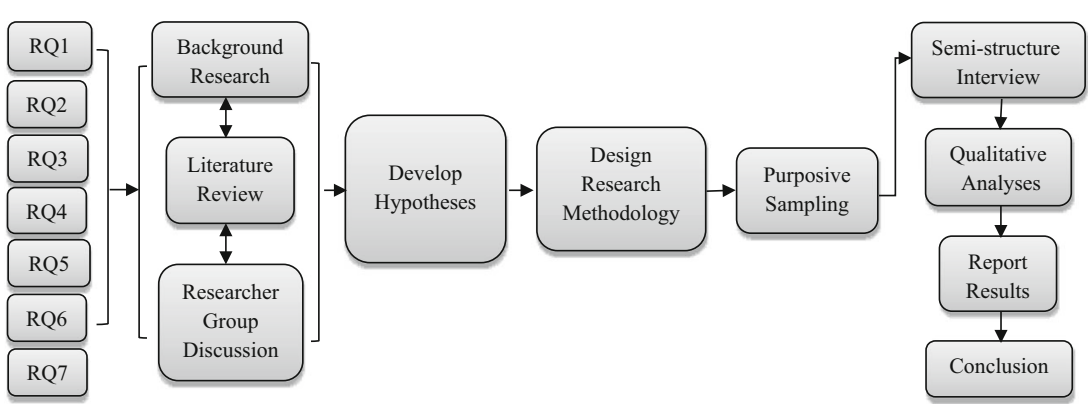


Table 1 Basic demographics information for participants interviewed in the present study

\begin{tabular}{lllllll}
\hline Name & Age & Gender & $\begin{array}{l}\text { Marital } \\
\text { status }\end{array}$ & Education & Business & $\begin{array}{l}\text { Quarantine } \\
\text { time (months) }\end{array}$ \\
\hline Fu & 32 & Female & Married & University & Clothing shop & 2 \\
Jian & 35 & Male & Married & Middle school & Construction Materials shop & 2 \\
Jin & 39 & Female & Married & University & Hardware wholesaling & 1 \\
Fan & 47 & Female & Married & Middle school & Restaurant & 2 \\
Yu & 44 & Male & Married & High school & Yoga gym & 2 \\
Cin & 49 & Male & Married & University & Restaurant & 2 \\
Li & 45 & Female & Married & Primary school & Barber shop & 2 \\
Nie & 63 & Male & Married & Middle school & Photography store & 2 \\
Ying & 30 & Female & Married & University & Tutorial school & 2 \\
Lyu & 38 & Female & Married & Junior college & Travel agency & 2 \\
Yin & 39 & Male & Married & High school & Restaurant & 2 \\
Jia & 35 & Female & Married & Middle school & Small household electrical & 2 \\
Shu & 41 & Male & Married & University & Book store & 2 \\
Mei & 37 & Female & Married & University & Beauty salon & 2 \\
\hline
\end{tabular}

Names are changed for privacy reasons et al., 2018). The data analysis system was divided into three stages: open coding, axial coding, and selective coding. In the first step, the data was read repeatedly, with a recurring comparison and conceptualization of each line to obtain 380 codes. The second step of axial coding was characterized by induction-deduction, where the authors regrouped the 380 codes into 9 categories, and a basic paradigmatic model was built to explain the responses. When the information was saturated, the paradigm was refined in the third step. In this selective coding process, broader and more abstract concepts were drawn from the previous categories and subcategories, forming a generalized explanatory model for the researched topic.

\section{Results}

Out of 14 participants, 13 were interviewed face to face and one was done via mobile phone. Participants' quarantine time ranged from one to two months. Participants were all married, and their ages ranged from 30 to 63 . There were 6 males and 8 females. Five had obtained a bachelor's degree. Eight were currently self-employed and that business was run by themselves, their spouse, or a sibling. Among this group, one reported having to fire an employee due to the shutdown (travel agency owner), one was previously poised to hire an employee but had to forego that due to the shutdown (bookstore owner), and one had to fire employees but due to the owner's own reasons unrelated to COVDI-19 (beauty salon owner).

The analysis started with open coding, where three of the authors collected data, then examined, compared, and conceptualized it in stage 1. From that, 380 labels were created that referred to the meaning of participants' feelings, thoughts, experiences, and actions that related to psychological experiences from Data1. All the 380 labels were basically drawn out of Nvivo11 based on the participants' own language. Subsequently, the 380 labels were roughly regrouped to 21 categories based on similar properties. Next, axial coding was conducted, bringing the 21 categories together into 10 core categories after thorough examinations with an inductivedeductive approach. Open coding and axial coding were conducted repeatedly to explore Data2, Data3, Data4, and Data5 until information was saturated and 9 core categories emerged. During this further exploration, a new core category (hope) was found and another three were merged into already existed categories. The list of 380 labels is too long to be presented here.

\section{Core Categories}

\section{Category 1: Enjoyment of Life}

When COVID-19 was reported in China, it happened during the traditional Chinese New Year. This is usually the longest vacation that small business owners and the self-employed get to take during a year, representing a rare time of relaxation with family. When the news of the lockdown first spread, indicating that everyone had to stay at home instead of going to work, participants described a feeling of being "comfortable" and that they could "enjoy this vacation". "We were supposed to take our children and parents to travel around during this vacation...this epidemic stopped us...we just 
stayed at home and enjoyed this vacation" (Fu). At the beginning, "we were rather comfortable because all of a sudden we had no work...my husband and I (used to) have to work around the clock...We were very happy when it was said this vacation was extended" (Jin).

Contrary to female participants, some male participants grew more accustomed to the lockdown as it progressed: "at first I was always eager to go out...the two of us were busy with this career...the three of us (the couple and their child) rarely ate together...we ate together every day during that time. I cooked whatever they'd like. It's really warm and sweet" (Yu). An owner had just come back from a conference where a fellow attendee contracted COVID-19 soon afterwards, which made him very upset. Fourteen days later, he felt "relaxed". "I used to have no time for my family...I accompanied my children, my wife...I even learned to cook for them... such happiness, such pleasure I usually didn't experience" (Jian).

It is normal for small business owners and the selfemployed to have a busy life so that they usually have little time to spend with family, or to share experiences and feelings. The lockdown gave them the chance to do so. Most of them felt their bond with family getting closer than before and they realized how precious it was. Fu and her husband were college classmates but now her husband works in a different city. Fu said, "I thought our relationship got better during this time like back in college, we talked for a long time...this epidemic helped to build our family better". When talking about happiness experienced with family, Jian stated, "I felt like it helps close the distance between families... we came to cherish each other more, cherish family, and cherish time spent with kids".

\section{Category 2: Loss}

Financial loss was unavoidable since businesses had been totally shut down for more than two months. Due to the fact that schools were still shut down in May in Shandong province, Ying, a tutorial school owner said, 'It's May now, we probably won't have any income even 'till June...we have to pay for the rent, teachers' salaries, and other fixed expenses...we won't have any income for about half a year." Jin reported, "We prepared a great deal of products before New Year...which have an expiration date...we either made discounts or just disposed of them...we lost about 1 million (about \$140,000)". Lyu said, "after the epidemic, we didn't get a penny - instead severe loss". They all suffered great losses because of the shutdown, which included (depending on the nature of their businesses) the loss of food that decayed or had expired, still having to pay high rent and employees' wages, the cancellation of previous product orders, or the loss of future orders. However, at the same time, they were still required to pay for their own loans and other personal expenses despite a severe decrease in income, leading to escalating financial losses.

\section{Category 3: Emotional Disturbance}

Most of the Chinese population typically go back to work on January 8 th after a seven-day vacation. After January 16th (the end of school winter break), home-quarantine was extended which made people feel "stressful" and "anxious". Fu reported, "after January $16^{\text {th }}$, we started getting stressful... all my winter goods are there (in the shop)...we were supposed to expand our store this year. Anyways, I felt a little disconsolate". Fan, a restaurant boss said, "(I) was really depressed at that time...we only spent money...without income...later, I was worried that the goods prepared were about to rot away. (I) was really anxious." Lyu, the boss of a travel agency complained, "We not only didn't get benefits, but also suffered great loss...all the burden of the family was getting heavier than before...fairly heavy... (I) felt fairly awful". Jian said "The biggest pressure on me is the economic pressure...I couldn't fall asleep for several nights".

When talking about COVID-19, "(I) was fearful...what if the epidemic diffused...what if (my family and I) were caught" (Fan). "Manager Tian (Jin's husband) went to Wuhan before the New Year...he felt nothing (there)...we were fearful after he got back...police went to our home once...we were very fearful" (Jin).

\section{Category 4: Hope}

Concerning future plans, "hope" became an attractive concept in everyone's conversations. "Everyday (I) was hoping, hoping tomorrow or a week later...or someday when Academician Zhong Nanshan would say 'Ok (smile), it is ok to go out, to open the business, the epidemic is over'...we were hoping like this every day" (Jian). "At that time (I) was just hoping... when would (we) go out? When could the gym open? I...often watched if there were more people outside through the window...I was hoping it would be over soon... for ...(I) really experienced the feeling of losing freedom..."(Yu). "Now (I) was hoping the travel ban can be lifted domestically... it might shed a light on my travel career" (Lyu).

During that time, almost everyone was overwhelmed by information about COVID-19, whether they deliberately sought to learn it or not. "I was hoping the epidemic would be over soon...I'm a Christian....anyway I felt very heavyhearted every day when (I) saw the fatalities increasing" (Jian). "When (COVID-19) was difficult to control... (I) was very anxious. Later when some measures were taken, (I) thought there was much hope anyway" (Fan). 


\section{Category 5: Comparisons to Others}

It was understandable that our participants engaged in comparisons with others about how they felt confronting this formidable situation even if there were no questions specifically included in the interview on this process. They either felt "better" or more "upset" when they compared themselves to others. Fu stated, "(I'm) a little upset. If I work in a public institution (note by the authors: employees always get secure salaries working for public institutions)...I wouldn't have been influenced to such extent, like my parents (retired from a public primary school)...while I equivalently had no income". When compared to Wuhan residents, Fu became relaxed, saying, "Compared to Wuhan people, you can see how well we were". While Jian reported, "Compared to the lives of the whole world, my thing is really not a big deal...economic pressure is not as important as life." Others compared the current situation with past eras; for example, Jin said, "Most people would probably lose lives when there was this kind of plague at that time...this era is very good."

When talking about money, different people had developed unique attitudes during the time of home quarantine. Jin said, "no matter how much money we have, I have a big wish, that is we all keep safe and stay healthy...money is merely a worldly possession." While others started to spend less compared to pre-COVID-19, "I talked to my husband, we couldn't be big spenders anymore...we should keep it down...what if something happens...we must have money in hand...then we will feel secure" $(\mathrm{Fu})$.

\section{Category 6: Social Support}

During this tough time, many reported having a strong sense of support from spouses, parents, siblings, friends, local government, or business partners in different forms. Fu said, "My husband worried about me ...paid more attention to me...I would like to give myself a chance (to take bar examination)...my husband bought me books and said 'try it'...he gave me both moral support and economic support". In addition to support from friends and fellow Christians, Jian reported, "my wife and I stick together through thick and thin...she comforted me...we read the Bible, prayed, practiced spirituality together ... that encouraged me greatly".

Parents were also a great support for many. Jin said, "my parents-in-law said kind words for most of the time... (they) tried their best to cook rich food, and attend to our emotions, saying '...the priority is health....don't take risks trying to open the business'...this was positive encouragement that made us feel peaceful". As an only-child, Fu's parents gave her so much which even made her feel "guilty". She stated, "it seemed too much pressure and burden were put on my parents...they gave me all the best, looked after children for us, worried about me...helped me economically...(I) felt guilty more or less".

Three participants mentioned national support. Jin and Ying actually received national subsidies of 5 or 6 months for endorsement insurance that was originally paid by them to their employees. Jin reported, "after the policy was released, I was very satisfied...felt relieved." However, some others reported not feeling national support. Lyu said, "I only knew that three forms of insurance were exempted for three months...we don't know how it would be implemented yet...still such a mess". Yu said, "To me, the government didn't bring anything".

\section{Category 7: Patriotism}

Participants showed great patriotism during this disaster. They extolled how "good" the nation was. Fu said, "this epidemic... made sodality enhanced...the particularly good aspect was ... Yantai government provided public N95 masks...(only) charging $¥ 3.00$...the government has been fairly good”. Jin stated, "we're in a good era, good government leaders...from our point, we're very proud of (China)". Jian said, "President Xi did prioritize the people's health. Their control measures did work". Yu expressed, "I saw the government surely provided free treatment for confirmed cases and free help for those quarantine people (not now - noted by authors)...I thought the government did fairly well". "You can see the country valued this very much...it's gonna be fine after a while... national policies were so good...(I) felt like much hope" (Fan).

\section{Category 8: Making Change}

During this long-term quarantine and business shutdown, everyone had time to contemplate and tried to make new plans for the future. However, this was generally not the case prior to January 16th, when there was no sign that the lockdown would be lifted. "Especially (because of) the epidemic this year, we started to change...to reduce our spending... one of the influences (of the epidemic) on us is money management...after lunar January $16^{\text {th }}$, I started reading (for the bar examination)...the epidemic caused a sense of crisis in me... if you try to figure it out, you will find new chances...I must have two strings to a bow" (Fu). Fu repeated "try to figure it out (xiang ban fa in Chinese)" 12 times and "change" 19 times during the whole interview. She also admitted, "it's probably because of the stress of staying at home, (I) transformed it into reading... what else to do to change except reading". "We reflected during that time...the way we did shopping through WeChat had an impact on our traditional business... why don't we put our products online?" (Jin). Fan recalled, "we thought about it at that time...what if people get used to eating at home... (what if) only a few people go to restaurants...we will have to work for others...(or) try to stick gradually, reducing cost". 
Participants practiced many ways to cheer up or to fulfil themselves including reading, doing some exercises, calling friends or posting online. Fu sometimes posted videos on Douyin (Chinese version of Tiktok). She said, "sometimes I posted some things that disturbed me...like (one night) at 11:00 PM after the kids went to bed ...I started reading... reading...then I posted on Douyin... what am I reading this for?" Jin and her husband, Manager Tian kept learning during the quarantine time. She stated, "When the kids were studying...I did some reading ...Manager Tian read management books, he didn't stop online courses either." Jin talked about her husband, "He joined a running group... he ran... about 1-2 hours every day...he was getting more peaceful". The Yoga gym boss $\mathrm{Yu}$ said, "Under this circumstance of not going out...our whole family (started) practicing yoga...agitation was relived through exercises".

\section{Category 9: Obedience}

According to $\mathrm{Yu}$, "We Chinese people are very obedient... during this time, we all cooperated very well". Fu said, "Be an honest man (lao shi ren means a person who behaves well and listens to the authority). Do whatever the country allows you to do...when the country lets you out less, you don't go. As long as you listen to the country, it's going to be fine." When talking about the impact on his business by COVID-19 and the difficulties he faced, Jian sighed, "there was no way... if I continued to be stuck at home, and it's hard to handle it. There was no way for it". He repeated "there was no way" 6 times altogether. Like Jian, when Fan recalled her predicament, she used exactly the same expression "there was no way" 12 times. She said, "You see the restaurant couldn't open. There was no way, no way to run it. Surely confused... what's more, we dare not to go out. The point was we thought that being at home was contributing (to the control of COVID19)...the slogan at that time was staying at home is also a contribution...we had to wait "till we were allowed to go out...threw those (rotten food) away. No way...very anxious, they cost money; prices were high...but no way". She later continued, "Although you were upset, you had to accept it, right? You shouldn't go out to make trouble".

\section{Paradigmatic Model}

An explanatory paradigm model was then formed (see Fig. 2) by systematically ordering data, integrating structure and process, and capturing the evolutionary dynamics of mental state phenomena (Santos et al., 2018). This model consisted of components known as the "5 Cs": context, causal conditions, intervening conditions, strategies and consequences as suggested by Strauss and Corbin (Chen, 2000; Santos et al., 2018).
In this model we see that the context of COVID-19 caused the forcible shutdown of business and quarantine conditions. As a result, mental states progressed from enjoyment of life, to perceptions of loss, to emotional disturbance, and then to hope. These mental states were impacted by intervening conditions (e.g. national measures, social support, and feelings of patriotism), personal strategies to cope (e.g. exercising, studying, social comparisons), and the consequences of evolving mental states (e.g. to make changes and to be obedient).

\section{Context}

As mentioned previously, within a very short time frame, life was dramatically transformed over the course of the holiday and festival period in China due to COVID-19. The potential for widespread chaos was seemingly suppressed by forcible home quarantine. While some level of restored order could be observed, on the surface this may have been the "tip of the iceberg". It still remains to be seen what types of consequences are yet to be uncovered below this "iceberg".

\section{Causal Conditions}

Above the iceberg, almost all businesses were shut down except those basic supply stores and factories. People were ordered to stay at home and only allowed to go shopping once or twice a week. Nearly half of China was locked down, which was not lifted until March 8th when people had been physically isolated for more than two months.

\section{Phenomena (Mental State)}

Under the iceberg, due to the quarantine, people's mental states showed considerable variability. The lockdown occurred simultaneously with the festival when most Chinese people were on a rare vacation period, especially for those who tend to work long and hard hours. For many of these individuals, the initial stages of the quarantine in particular provided some "break" from the normally busy life and some were happy to have a longer vacation time with family to enjoy life, particularly in areas like Shandong which was far from the epicenter of the virus. It provided a time to connect with family, build relationships and strengthen bonds which was cherished by many. In contrast, this was also a time of financial strain where many experienced lost income, expiration of goods, and forfeiture of incoming/future orders in combination with high personal expenditures, such as costly rent and existing personal/business loans, which contributed to psychological disturbances such as stress, anxiety, and fear. However, the feeling of hope for the future provided a buffer from these issues for many, as they looked expectantly towards better times in the future. 
Fig. 2 Pragmatic model linking intervening conditions, strategies, and consequences to mental states following quarantine from COVID-19

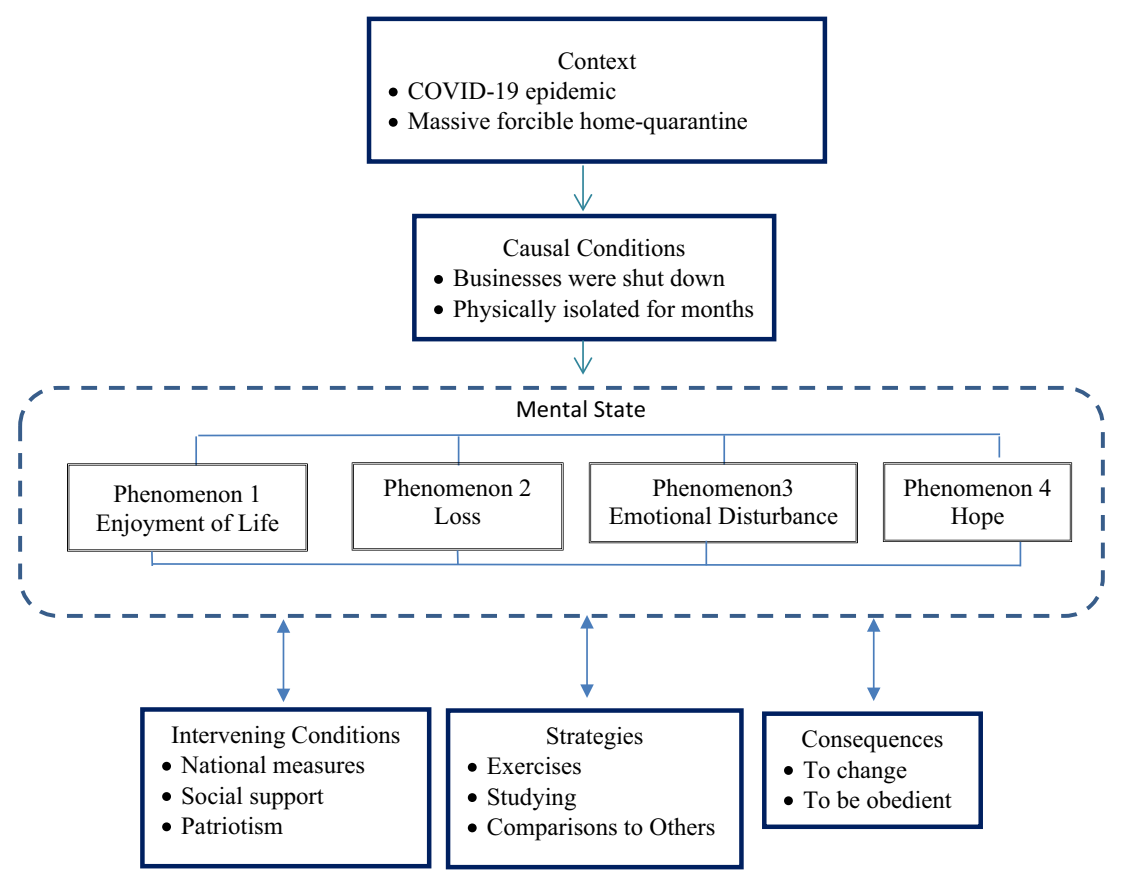

\section{Intervening Conditions}

In order to control COVID-19, the government took many measures, like organizing medical staff from across the country in support of Wuhan and Hubei Province and took steps to circulate information on prevention. Front-line workers also stepped forward in providing continual care for those in need across the country. In addition, an important intervening condition that emerged in the present study was the experience of social support from family and friends, such as video chats with parents who usually lived alone and comfort from a spouse. Another important intervening condition was the experience of patriotism, which is a well ingrained spirit among Chinese people and deeply impacted the path of people's mental state.

\section{Strategies to Cope}

Interviewees adopted various ways to relieve the negative consequences of the forced quarantine. The common solution was to do exercises, such as running with friends, practicing yoga with family, or dancing. Others took this as a time to find new challenges, such as taking time to study. The most typical way of coping, however, was through personal comparisons. These included comparison with those at the epicenter, with those who were less fortunate, and with others in different locations or times that might be more adversely impacted by COVID-19. This downward comparison served to leave many feeling grateful and blessed. In particular, many came to a point of buffering the negative psychological outcomes by recognizing the relative value of health over financial loss.

\section{Consequences}

Effective coping strategies led people to relax, and prompted many to try altering their current situation or to plan for future change. Some studied, some pursued the possibility of another career, and some examined new possible business strategies or business models for the future.

Although they longed to open their business - particularly given the financial struggles faced by these small and selfemployed business owners - many recognized that the best way to avoid longer term consequences was to be obedient to the plan. Even amidst the varying approaches to dealing with the day-to-day struggles of the quarantine and forced shutdown of their businesses, there was a strong sense among many to yield to the social responsibility of staying at home to confront the threat of COVID-19.

\section{Central Category}

In the selective coding, continuous comparison and analysis of the data was performed to refine the previously defined categories and subcategories, which led to the integration of data in the identification of the central category as shown in Fig. 3. As previously noted, there was some inconsistency in mental states as a result of the home-quarantine, with some showing more positive and some showing more negative outcomes. Further, for many these states did appear to fluctuate sometimes gradually over time and sometimes more abruptly. Nonetheless, the specific path depended on three main factors including inner strength, a common obedient attitude, and social support. More specifically, inner strength was 


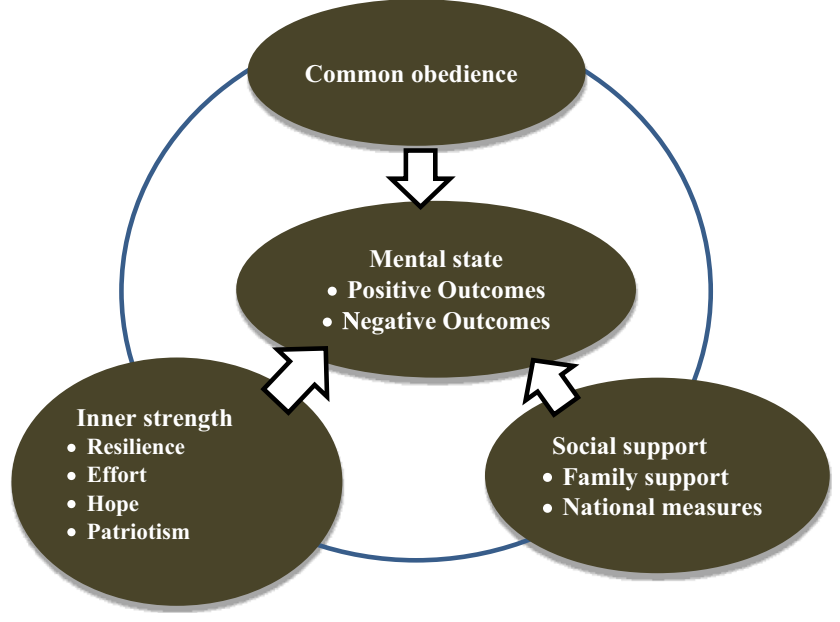

Fig. 3 Factors influencing mental state during forced quarantine among small business owners and the self-employed in China

demonstrated by the thoughts, actions, and orientation towards change that manifest itself in an optimistic attitude towards life at home, a resilience when confronting these difficulties, personal efforts to make positive change, and a hope for the future. In terms of support, with the exception of $\mathrm{Fu}$ who mentioned the purchase of N95 masks from the local government, nobody else mentioned national support as a direct positive impact during the time of quarantine. However, several did received insurance subsides from the government that made them feel better after quarantine, and the specific measures taken by the government to control COVID-19 did appear to make most feel more secure. What was evident, though, was that the principal support which contributed to more positive mental states was support from family members. Finally, there was a fairly common thread of obedience that seemed to improve mental states. This was manifest as a general attitude that this is a common and shared quality among Chinese people that contributes to a feeling of resilience, and endurance in adjusting to challenges and struggles in life.

\section{Discussion}

The present study is unique in that the focus was on the psychological impact of COVID-19 on small business owners and the self-employed who would be particularly hard-hit by the severe economic impact of the forced lock-down in China. With respect to the first hypothesis, as expected it appears that the long-term home-quarantine in China did have a psychological impact on this sample, but the nature of this impact was not entirely in line with the second hypothesis in that there appeared to be a tendency towards a more positive mental state among many at early and latter stages of the quarantine. This is another relatively unique contribution to the limited existing research in that there has been little focus on potential positive personal outcomes of the forced lockdown situation due to COVID-19. On the surface this appears to contradict other studies that have noted numerous negative consequences related to COVID-19, including stress, depression, irritability, insomnia, fear, confusion, anger, frustration, boredom, and stigma associated with quarantine, some of which were found to persist even after the quarantine was lifted (Brooks et al., 2020). It should be noted, though, that the participants in this study did suffer adverse outcomes but those appeared to be most evident in the middle of the quarantine period when the lockdown was extended, but these outcomes did not necessarily persist as many participants seemed to show a return to a positive mental state. In the end, this demonstrates that the impact of the lockdown is complex and does not necessarily lead to a linear sequence of negative consequences, which is an important implication for research in this area.

Participants appeared to progress through three meaningful phases that indicated an emotional evolution in line with how COVID-19 was addressed and as the lockdown developed over time. The first phase occurred at the beginning when the new Coronavirus was initially introduced and announced as a contagious disease. At this point many would be in a positive mood as they were in the midst of celebrating the most important Chinese holiday festival. For our participants who are generally very busy in their daily business routines, the news of the lockdown provided a much-needed break and a chance to reconnect with family which brought on a strong positive mental state. This would be in line with the well-known Chinese philosophy of "Shun Shi Er Wei" ("let nature take its course") in that small business owners and the self-employed looked to take advantage of the adverse circumstances as they happened. Therefore, participants tended to enjoy life with loved ones because the quarantine gave them this unique opportunity.

The second phase emerged as the quarantine progressed and significant concerns materialized among many small business owners and the self-employed due to uncertainty about their business and their future. As the shutdown progressed there were many unexpected and unanticipated outcomes that surfaced. For example, many products that had been prepared for the New Year would go unsold or could expire, rents and loans still needed to be paid despite a loss of income, and the health-related dangers of COVID-19 continued to rise. This led to many adverse consequences including anxiety, stress, arousal, and fear. This was in addition to the rising concerns over health risks associated with COVID-19. However, participants showed resilience as they utilized various mechanisms to cope. These included seeking social support (mainly from family members), taking confidence in the national measures to control COVID-19, and making comparison to other people and contexts. 
Social support can buffer stress, and anxiety, through the sharing of information, by providing an opportunity to discuss feelings and experiences, and by increasing the feeling of being cared for. This outcome is in line with previous research on Strain Theory, where social support has been shown to buffer the impact of strain on subsequent psychological distress (Liu et al., 2019; Zhou et al., 2018). In a similar way, a confidence that measures were being taken to control COVID19 could improve the longer-term outlook and give individuals a sense that there is future hope. According to Wang et al. (2020b), the psychological impact of risks associated with the pandemic can be dramatically reduced when people feel that they are receiving current and accurate information about COVID-19. Likewise, confidence in doctors can also represent protective factors for negative psychological outcomes due to COVID-19 (Wang et al., 2020c). In turn, this can subsequently increase adherence to personal protective factors, such as wearing masks, engaging in hand hygiene, and distancing which can moderate psychological consequences such as stress, anxiety, and depression (Rahman et al., 2021; Wang et al., 2020a). Further, comparisons with others can buffer negative emotional states by giving a sense of relative advantage; for example, the idea that there are many in Wuhan who were much more adversely affected, that many businesses were hit harder, that some in different regions or different eras did not have the same level of medical or technological advances, and that some were even trapped far from their homes and families during this crisis. Festinger (1954) suggested that people have a strong tendency to evaluate themselves in comparison to others. In this case, through downward comparisons (Kesici \& Erdoğan, 2010), participants may feel better knowing that comparatively they are better off than many others. As a result, this process might buffer against the negative psychological consequences during the lockdown.

Another factor that appeared to lead to an improvement in mental states was a sense of patriotism. This was seen as a belief in the strength of China as a nation and its ability to eventually control the spread of the virus. They noted that the government had great resolve and compassion for the people. Many were thankful that the government paid for treatment of infected individuals and noted how authoritative the government was in ordering such a drastic measure to address the issues of COVID19. This is consistent with other research that noted lower levels of anxiety and depression among those who felt that early government interventions were crucial in minimizing the spread of infection and eventual death rates (Le et al., 2020). This may impart a sense that the government and the nation in general are concerned about individual well-being. In interviews with COVID patients, Hao et al. (2020) found more positive affect and attitudes among those who perceived that the country, government, and medical profession cared about them. In the present study, there was a great expression of pride in being Chinese - to the point where some even attempted to volunteer to assist those impacted in Wuhan. In fact, one participant even served as a front-line worker as a party member. This patriotic expression is likely due to the fact that this patriotic attitude runs consistently through the education system from kindergarten through university. Further, this is maintained after formal schooling through Communist Party activities, the media, new technologies and mass entertainment (Chai et al., 2020; Guo, 2019). Acting on this patriotism (specifically to do things for the betterment of China and the Chinese population) has become the norm. Love for the country runs deep in China, which may have led to increased positive psychological states such as faith, optimism, confidence, assurance, grit, and security. These may have supplanted many of the negative emotions that could have potentially emerged. For example, one might fear what could happen to their business, but the patriotic notion that China is strong, they will survive these challenges, and will support its people, could potentially transition into a feeling of confidence and hope for the future.

Along with a strong sense of patriotism, the Chinese also show a desire for obedience which was important during the early stages of the lockdown in particular. This has been observed by prominent experts (Jiang, 2011; Smith \& Li, 2010) who note that the Chinese are a widely obedient group to authorities. Participants in this study were resolute in their obedience to the quarantine, even to the point of shutting down their businesses despite immense personal costs. This was not a mere act of compliance though, as there was an expressed sentiment of wanting to stay accountable in helping to reduce the personal and social threat, and to reduce the potential spread of the virus as happened in other countries in a similar context (Digiovanni et al., 2004; Toronto SUN, 2020). And while this could still lead to a negative mental state (particularly in the mid stages of the quarantine), participants were nonetheless able to translate this to a more positive state by making the best of the situation through connecting with family, staying in shape and exercising, or studying. Being obedient appeared to help participants gain more endurance and inner strength to deal with this tough situation.

As time passed, participants showed grit and determination in dealing with loss and adverse emotions, while holding on to hope for future progress and change. When noting the Chinese character Pan (hope), many smiled as their faces lit up. They clearly looked forward to a time when they could return to previous activities, to go out and move among the population and to open their business once again. This character Pan bears the expectation of future life, expressing good will for terminating this unexpected and unwelcomed lockdown, and resuming their journey of life. 


\section{Limitations and Future Directions}

This study was conducted nearly two months after the massive home-quarantine was ended when almost all participants reopened their business except $\mathrm{Mr}$. Yu who owns a yoga gym that was still suspended due to the lockdown regulations. In some cases, this might impact the accuracy of recall of events or experiences, while in other instances participants might downplay emotions unintentionally since they were now in a relatively "normal" condition. Therefore, true mental states which existed during the lockdown might not have been fully revealed in this study. As such, future research may benefit from examinations of psychological outcomes during various periods of lockdown as they occur in a more longitudinal manner.

It should also be noted that the participants in this study did not reside in the epicenter or areas most strongly impacted by COVID-19. In this respect, these participants did not have to deal with the illness or the threat of illness to the same degree as those in areas like Wuhan. Similarly, the lockdown would not have lasted as long, so comparatively the threat to their livelihood would not have been as severe. As a result, the mental states of those in areas more dramatically impacted by this threat may show a unique pattern, particularly in terms of negative thoughts and feelings. The current outcomes, nonetheless, should still apply to the large proportion of small and self-employed business owners in China. Future research could potentially look to draw comparisons of participants in varying regions, including those with greater and lesser infection rates or lockdown durations, to understand potential similarities and differences in mental states and coping strategies.

Another limitation concerned the conduct of Grounded Theory. All participants were interviewed under the same guide constructed beforehand, without following a longerterm process that provides refinement to the guide after an interview is analyzed. Rather, minor adjustments were conducted after the former interview and not after analysis of the former data. While this process was necessitated by the urgency of this naturally occurring catastrophic event, this might have impacted the nature of the responses.

In terms of implications, the present findings highlight the need for authorities (e.g. government, school boards, doctors, employers) to provide early, accurate, and trustworthy information about events such as COVID-19, which has been confirmed in previous research (Rahman et al., 2021; Wang et al., 2020c). Similarly, it emphasizes the importance of providing a high degree of support at all levels of a person's life space including family, community, organizations, the medical industry, and government. These should not only impact positive mental state, but also interactively with personal protective activities such as distancing, use of masks, and sanitizing practices (Rahman et al., 2021; Wang et al., 2020a), which should lead to more widespread physical and psychological health improvements, and ultimately "hope" for the future.

Another implication is that there is a strong longer-term need to pursue effective strategies for mental health services to address and treat negative mental health consequences during events such as the pandemic and subsequent lockdown in China. One effective means of accomplishing this could be through the use of telephone or virtual based therapy approaches. Just as Antonopoulou et al. (2021) found that the academic landscape has been changing in the face of COVID-19, where digital skills in addition to good communication are crucial for good leadership, the same could be argued in many ways for the mental health field. In this respect, there is growing necessity and demand for the development of digitally based therapeutic approaches. For example, there is growing evidence that digitally based Cognitive Behavior Therapy can be a low-cost and effective means of treatment, in particular for COVID-19 patients (Ho et al., 2020; Ho et al., 2020; Li et al., 2020; Zhang \& Ho, 2020). As such, the development and promotion of this type of therapy could exponentially improve mental well-being during harsh conditions of lockdown when travel may be tightly restricted and threat of spread of infection is great.

\section{Conclusions}

The present study showed that the impact of the long-term home-quarantine on small business owners and selfemployed participants is complex and depends on a number of situational and individual factors. As expected, there were noteworthy negative consequences to the forced lockdown economic and psychological issues that the scientific community should continue to investigate for the health and safety of everyone. But the present findings also highlight the human capacity to cope in seemingly terrible conditions in that, somewhat unexpectedly, positive mental states emerged at various points from these negative circumstances. Specifically, mental states were found to fluctuate across the duration of the quarantine, which varied from relaxation at the beginning to fear and anxiousness in the middle, mixed with resolution to change and hope for the future towards the end. An important factor that impacted the initial positive mental state were a welcomed opportunity to relax and spend time with family to reconnect. During the middle stage, stress, fear, and anxiety over lost business and revenue led to a rise of negative mental states. However, patriotism, obedience, social support, inner strength, and hope for the future led to a return of a positive psychological state towards the conclusion of the quarantine. In this respect, the scientific community should continue to pursue evaluations of the factors that buffer or mitigate negative mental states, such as social support, confidence in medical information, a sense of belonging, and future hope. 
Data Availability Available upon request.

\section{Declarations}

Ethics Approval All study protocols were approved by the Research Ethics Boards of Weifang Medical University.

Consent to Participate Informed consent was obtained in writing from all participants.

Conflicts of Interest/Competing Interests There are no conflict of interest/competing interests for this research.

\section{References}

Antonopoulou, H., Halkiopoulos, C., Barlou, O., \& Beligiannis, G. N. (2021). Transformational leadership and digital skills in higher education institutes during the COVID-19 pandemic. Emerging Science Journal, 5. https://doi.org/10.28991/esj-2021-01252.

Brooks, S. K., Webster, R. K., Smith, L. E., et al. (2020). The psychological impact of quarantine and how to reduce it rapid review of the evidence. Lancet, 395, 912-920. https://doi.org/10.1016/S01406736(20)30460-8.

Chai, L., Wei, J., Han, Y., Zhang, J., \& Hennessy, D. A. (2020). Political elite selection in contemporary Chinese higher education. China: An International Journal, 18, 143-160.

Chen, X. (2000). Qualitative research in social sciences (in Chinese) (1 ed. Vol.). Education Science Publishing House.

Dailey, S. F., \& Kaplan, D. (2014). Shelter-in-place and mental health an analogue study of well-being and distress. Jounal of Emergency Management, 12(2), 121-131. https://doi.org/10.5055/jem.2014. 0166.

Digiovanni, C., Conley, J., Chiu, D., et al. (2004). Factors influencing compliance with quarantine in Toronto during the 2003 SARS outbreak. Biosecurity and Bioterrorism, 2(4), 265-272.

Dimaschko, J., Shlyakhover, V., \& Iabluchanskyi, M. (2021). Why did the COVID-10 epidemic stop in China and does not stop in the rest of the world? (Application of the Two-Component Model). SciMedicine Journal, 3(2), 88-99. https://doi.org/10.28991/ SciMedJ-2021-0302-2.

Festinger, L. (1954). A theory of social comparison processes. Human Relations, 7(2), 117-140. https://doi.org/10.1177/ 001872675400700202 .

Gunia, A. (2020). China's draconian lockdown is getting credit for slowing coronavirus. Would it work anywhere else? Retrieved April 19, 2020, from https://time.com/5796425/china-coronaviruslockdown/

Guo, R. (2019). China update patriotic education push to forge stronger national identity-including in Hong Kong, South China Morning Post. Retrieved April 14, 2020 from https://www.scmp.com/news/ china/politics/article/3037606/china-updates-patriotic-educationpush-forge-stronger-national.

Gyasi, R. M., Yeboah, A. A., Mensah, C. M., et al. (2019). Neighborhood, social isolation and mental health outcome among older people in Ghana. Journal of Affective Disorders, 259, 154 163. https://doi.org/10.1016/j.jad.2019.08.024.

Hao, F., Tam, W., Hu, X., et al. (2020). A quantitative and qualitative study on the neuropsychiatric sequelae of acutely ill COVID-19 inpatients in isolation facilities. Translational Psychiatry, 10, 355. https://doi.org/10.1038/s41398-020-01039-2.

Ho, C. S., Chee, C. Y., \& Ho, R. C. (2020). Mental health strategies to combat the psychological impact of COVID-19 beyond paranoia and panic. Annals of the Academic of Medicine Singapore, 49(3), $155-160$.

Huang (editor), R. (2020). 31 provinces launched level-one response to major public health emergencies in China Retrieved April 19th, 2020, from http://www.taihainet.com/news/txnews/cnnews/sh/ 2020-01-29/2350523.html

Huaxia (editor). (2020). China focus: Schools start online courses as epidemic control postpones new semester Retrieved April 19, 2020, from http://www.xinhuanet.com/english/2020-02/17/c 138792006.htm

Jiang, H. (2011). Coase: Obedience is not a good characteristics of Chinese (in Chinese), Retrieved April 20, 2020 from http:// finance.ifeng.com/opinion/zjgc/20111215/5278267.shtml.

Kesici, S., \& Erdoğan, A. (2010). Mathematics anxiety according to middle school students' achievement motivation and social comparison. Education, 131(1), 54-63.

Kim, H. C., Yoo, S. Y., Lee, B. H., et al. (2018). Psychiatric findings in suspected and confirmed middle east respiratory syndrome patients quarantined in hospital: A retrospective chart analysis. Psychiatry Investigation, 15(4), 355-360. https://doi.org/10.30773/pi.2017.10. 25.1.

Langton, K. (2020). China lockdown: How long was China on lockdown? Retrieved April 19, 2020, from https://www.express.co.uk/ travel/articles/1257717/china-lockdown-how-long-was-chinalockdown-timeframe-wuhan

Le, H. T., Lai, A., Sun, J., Hoang, M. T., Vu, L. G., Pham, H. Q., Nguyen, T. H., Tran, B. X., Latkin, C. A., Le, X., Nguyen, T. T., Pham, Q. T., Ta, N., Nguyen, Q. T., Ho, R., \& Ho, C. (2020). Anxiety and depression among people under the nationwide partial lockdown in Vietnam. Frontiers in Public Health, 8, 589359. https://doi.org/10. 3389/fpubh.2020.589359.

Lee, S. M., Kang, W. S., Cho, A. R., et al. (2018). Psychological impact of the 2015 MERS ourtbreak on hospital workers and quarantine hemodialysis patients. Comprehensive Psychiatry, 87, 123-127. https://doi.org/10.1016/j.comppsych.2018.10.003.

$\mathrm{Li}$, J., et al. (2020). The effect of cognitive behavioral therapy on depression, anxiety, and stress in patients with COVID-19: A randomized controlled trial. Frontiers of Psychology, 30. https://doi.org/10. 3389/fpsyt.2020.580827.

Liu, J., Li, F., \& Lian, Y. (2008). Investigation of reliability and validity of the social support scale (in chinese). Jounal of Xinjiang Medical University, 31(1), 1-3.

Liu, Y., Zhang, J., Hennessy, D. A., \& Zhao, S. (2019). Psychological strains, depressive symptoms, and suicidal ideation among medical and non-medical staff in urban China. Journal of Affective Disorders, 245, 22-27.

Maunder, R., Hunter, J., Vincent, L., et al. (2003). The immediate psychological and occupational impact of the 2003 SARS outbreak in a teaching hospital. Canadian Medical Association Journal, 168(10), $1245-1251$.

National Health Commission of the People's Republic of China. (2020). A high-level experts's novel coronavirus pneumonia briefing by NHC. Retrieved January 21th, 2020, from http://www.nhc.gov.cn/ xcs/s7847/202001/8d735f0bb50b45af928d9944d16950c8.shtml

PTI. (2020). Lift lockdown gradually to prevent 'second wave' of coronavirus, experts warn China as Wuhan allows people to travel. Retrieved April 25, 2020, from https://www.india.com/news/ world/lift-lockdown-gradually-to-prevent-second-wave-ofcoronavirus-experts-warn-china-as-wuhan-lifts-travel-ban3994696

Rahman, M.M., Jhinuk, J.M., Nabila, NH, Yeasmin, M.T.M., Shobuj, I.A., Sayma, T.H., Faruk F., \&. Shah, S.H. (2021). Knowledge, attitude, and practice towards COVID-19 during the rapid rise period: A cross-sectional survey among public university students of Bangladesh. SciMedicine Journal, 3(2), 116-128. Doi: https://doi. org/10.28991/SciMedJ-2021-0302-4 
Ren, R., Zhang, J., \& Hennessy, D. A. (2018). Psychological strains and psychological distress among Chinese rural migrant workers. Asian and Pacific Migration Journal, 27, 231-241.

Santos, J. L. G., Cunha, K. S., Adamy, E. K., Backes, M. T. S., Leite, J. L., \& Sousa, F. G. M. (2018). Data analysis: Comparison between the different methodological perspectives of the Grounded Theory. Jounal of School of Nursing University of Sao Paulo, 52, e03303. https://doi.org/10.1590/S1980-220X2017021803303.

Smith, A. H., \& Li (interpreter), M. (2010). Chinese characteristics (in chinese) (1 ed.). Shanxi Normal University Press.

Toronto SUN. (2020). Covidiots-19: Anti-quarantine protest 'best thing... Ever', Retrieved March 2, 2020 from https://torontosun.com/news/ world/covidiots-19-anti-quarantine-protest-best-thing-ever.

Tran, B. X., Nguyen, H. T., Le, H. T., Latkin, C. A., Pham, H. Q., Vu, L. G., Le, X., Nguyen, T. T., Pham, Q. T., Ta, N., Nguyen, Q. T., Ho, C., \& Ho, R. (2020). Impact of COVID-19 on economic well-being and quality of life of the Vietnamese during the national social distancing. Frontiers in Psychology, 11, 565153. https://doi.org/ 10.3389/fpsyg.2020.565153.

Usher, K., Bhullar, N., \& Jackson, D. (2020). Life in the pandemic social isolation and mental health (accepted, unedited). Jounal of Clinical Nursing. https://doi.org/10.1111/jocn.15290.

Wang, X., \& Zhang, G. (2020). Do 5 million Wuhan people flee or leave normally from the academic perspective? (in Chinese) Retrieved April 24, 2020, from https://www.sohu.com/a/369206973_260616

Wang, C., Chudzicka-Czupała, A., Grabowski, D., Pan, R., Adamus, K., Wan, X., Hetnał, M., Tan, Y., Olszewska-Guizzo, A., Xu, L., McIntyre, R. S., Quek, J., Ho, R., \& Ho, C. (2020a). The association between physical and mental health and face mask use during the COVID-19 pandemic: A comparison of two countries with different views and practices. Frontiers in Psychiatry, 11, 569981. https://doi. org/10.3389/fpsyt.2020.569981.

Wang, C., Pan, R., Wan, X., Tan, Y., Xu, L., Ho, C. S., \& Ho, R. C. (2020b). Immediate psychological responses and associated factors during the initial stage of the 2019 Coronavirus disease (COVID-19) epidemic among the general population in China. International Journal of Environmental Research and Public Health, 17(5), 1729. https://doi.org/10.3390/ijerph17051729.
Wang, C., Pan, R., Wan, X., Tan, Y., Xu, L., McIntyre, R. S., Choo, F. N., Tran, B., Ho, R., Sharma, V. K., \& Ho, C. (2020c). A longitudinal study on the mental health of general population during the COVID-19 epidemic in China. Brain, Behavior, and Immunity, 87, 40-48. https://doi.org/10.1016/j.bbi.2020.04.028.

World Health Organization. (2020). World Health Organization. Novel Coronavirus (2019-NCOV) situation report-1.

Xiao, S. (1994). Theoretical basis and application of social support rating scale (in Chinese). Journal of Clinical Psychiatry, 4(2).

Xie, N., Wang, Z., \& Zhao, J. (2017). Reliability and validity test for 12item Grit Scale in Chinese adults (in Chinese). China Journal of Health Psychology, 25(6), 893-896. https://doi.org/10.13342/j. cnki.cjhp.2017.06.25.

Zhang, J. (2005). Conceptualizing a strain theory of suicide. Chinese Mental Health Journal, 19(11), 58-782.

Zhang, Y. (2020). Hubei raises health emergency response to highest level. Retrieved April 19, 2020, from https://www.chinadaily.com. $\mathrm{cn} / \mathrm{a} / 202001 / 24 /$ WS5e2a8f83a3101282172731fa.html

Zhang, M. W., \& Ho, R. C. (2020). Moodle: The cost effective solution for internet Cognitive Behavioral Therapy (I-CBT) interventions. Technology and Health Care, 25(1), 163-165. https://doi.org/10. 3233/THC-161261.

Zhang, J., Liu, Y., \& Hennessy, D. A. (2016). Effects of psychological strains on Chinese college students' depression and suicidal ideation. Journal of Forensic Psychology, 1, 106. https://doi.org/10. 4172/2475-319X.1000106.

Zhang, L., Wang, J., An, L., et al. (2020). Good policies should be seen and touched-current living situation of small business owners and self-employed people (in Chinese) Retrieved April 25, 2020, from http://dz.jjckb.cn/www/pages/webpage2009/html/2020-04/09/ content 63104.htm

Zhou, Q., Zhang, J., \& Hennessy, D. A. (2018). The role of family absolute and relative income in suicide among Chinese rural young adults: Mediation effects of social support and coping strain. Journal of Public Health, 41, 609-617.

Publisher's Note Springer Nature remains neutral with regard to jurisdictional claims in published maps and institutional affiliations. 